Supporting Information

\title{
Uniform Li Deposition Sites Provided by Atomic Layer Deposition for Dendrite-Free Lithium Metal Anode
}

Bing Zhao, ${ }^{\text {a,b }}$ Bobo Li, ${ }^{\text {a }}$ Zhixuan Wang, ${ }^{\text {a }}$ Chuxiong Xu, ${ }^{a}$ Xiaoyu Liu,,${ }^{b}$ Jin Yi, ${ }^{b}$ Yong Jiang, ${ }^{\text {a,b, }}{ }^{*}$ Wenxian Li, ${ }^{\text {b,c }}$ Ying Li, ${ }^{\text {b,c }}$ Jiujun Zhang ${ }^{b}$

a School of Environmental and Chemical Engineering, Shanghai University,

Shanghai, 200444, China.E-mail: jiangyong@shu.edu.cn

${ }^{\mathrm{b}}$ Institute for Sustainable Energy/College of Sciences, Shanghai University, Shanghai 200444, China.

c School of Materials Science and Engineering, Shanghai University, Shanghai 200072, China 


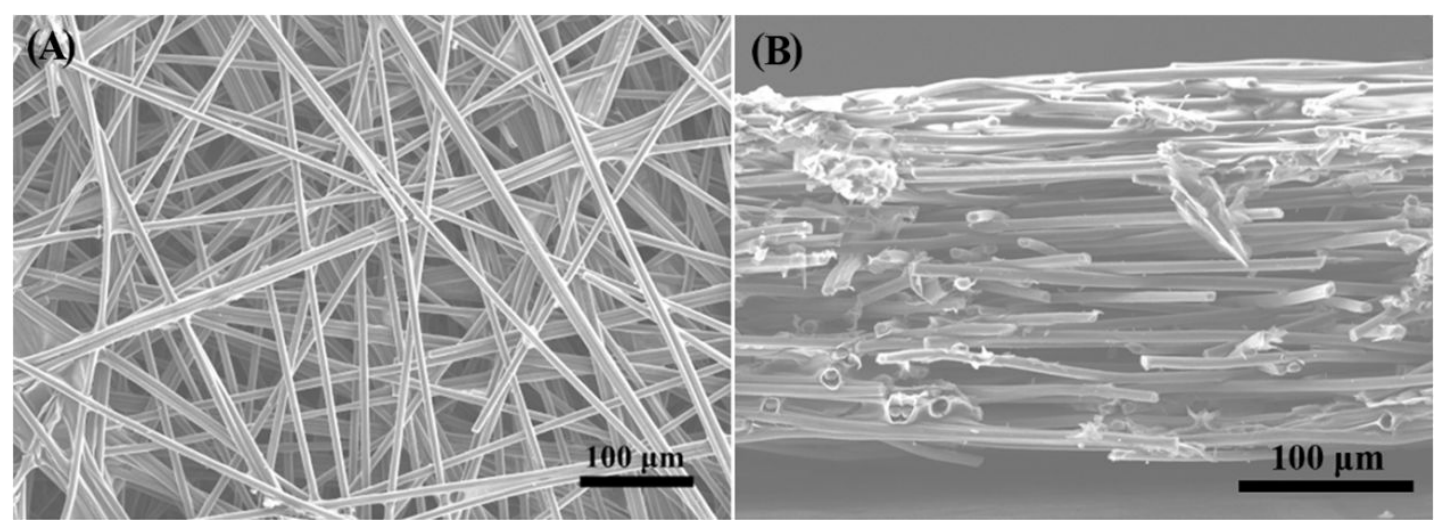

Figure S1. (A) Top view and (B) Cross-section SEM image of the pristine carbon fiber paper.

(A)

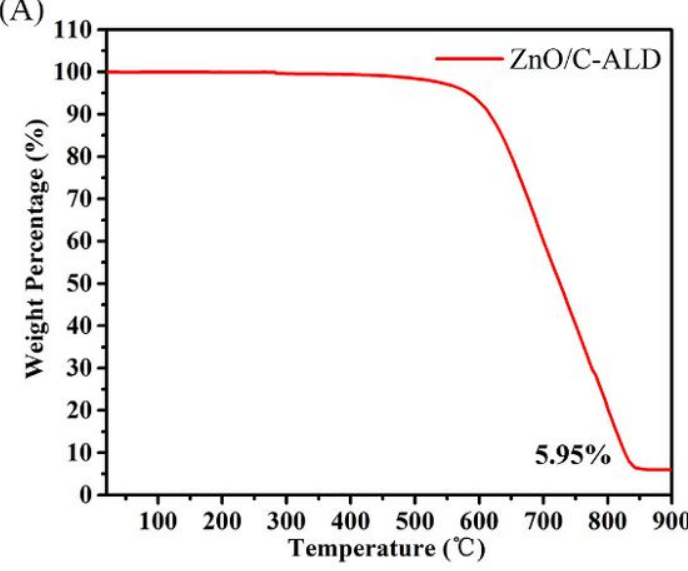

(B)

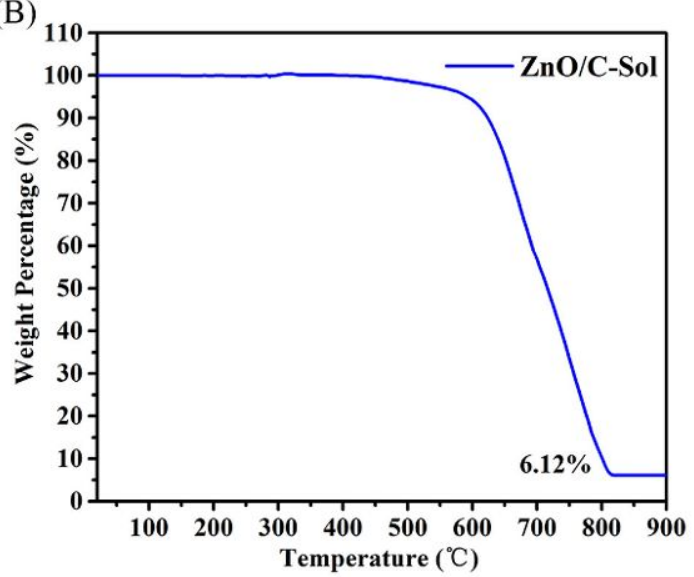

Figure S2. Thermogravimetric curves of (A) $\mathrm{ZnO} / \mathrm{C}-\mathrm{ALD}$ and (B) $\mathrm{ZnO} / \mathrm{C}-\mathrm{Sol}$ composite electrodes at air atmosphere. The residual weights correspond to the $\mathrm{ZnO}$ loading contents in the electrodes. It shows the similar $\mathrm{ZnO}$ contents are obtained for the $50 \mathrm{~nm} \mathrm{ZnO} / \mathrm{C}-\mathrm{ALD}$ and $1.0 \mathrm{M} \mathrm{ZnO/C-Sol} \mathrm{samples.}$ 

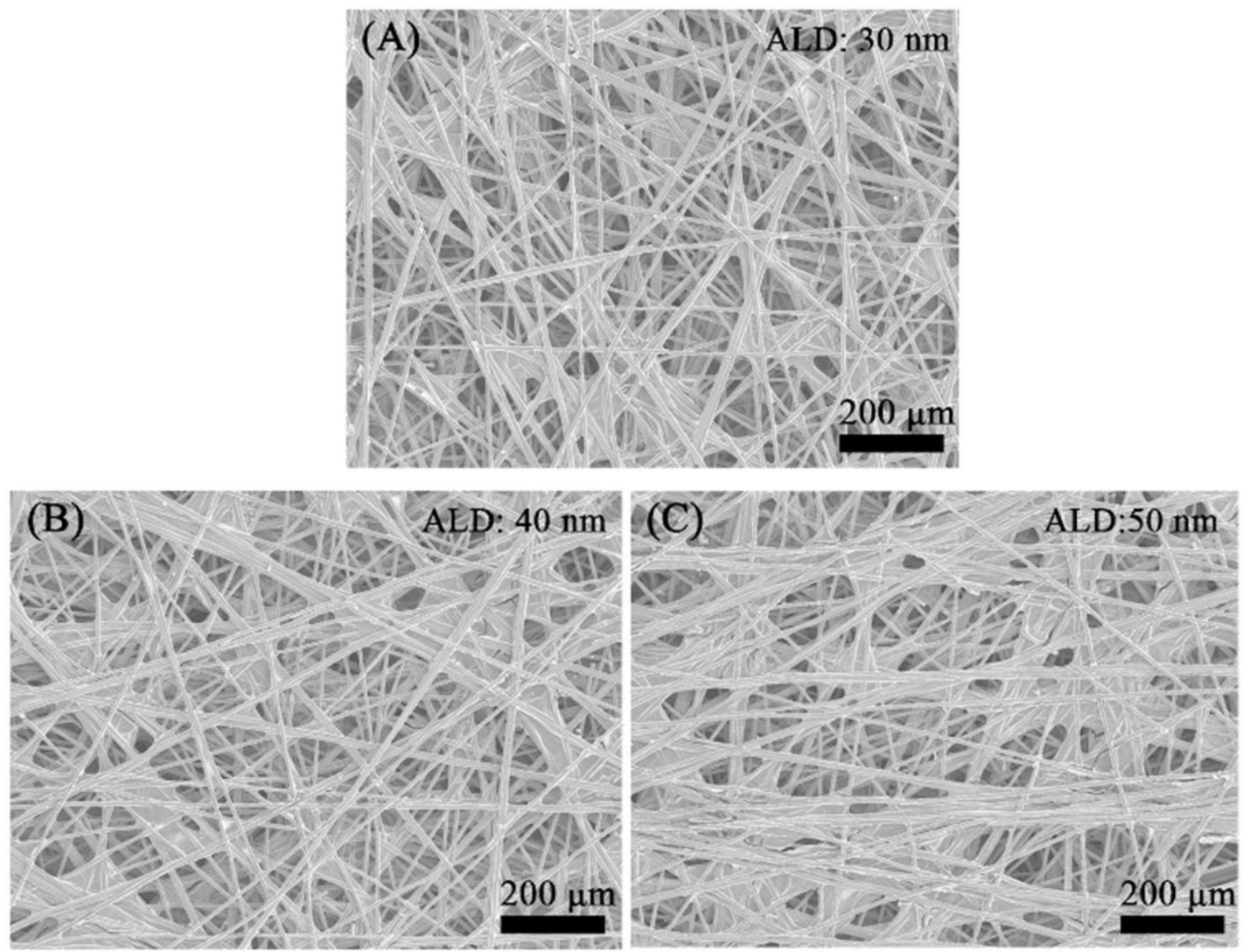

Figure S3. SEM images of $\mathrm{ZnO} / \mathrm{C}-\mathrm{ALD}$ samples with different $\mathrm{ZnO}$ coating thickness: (A) $30 \mathrm{~nm}$, (B) $40 \mathrm{~nm}$, and (C) $50 \mathrm{~nm}$. 

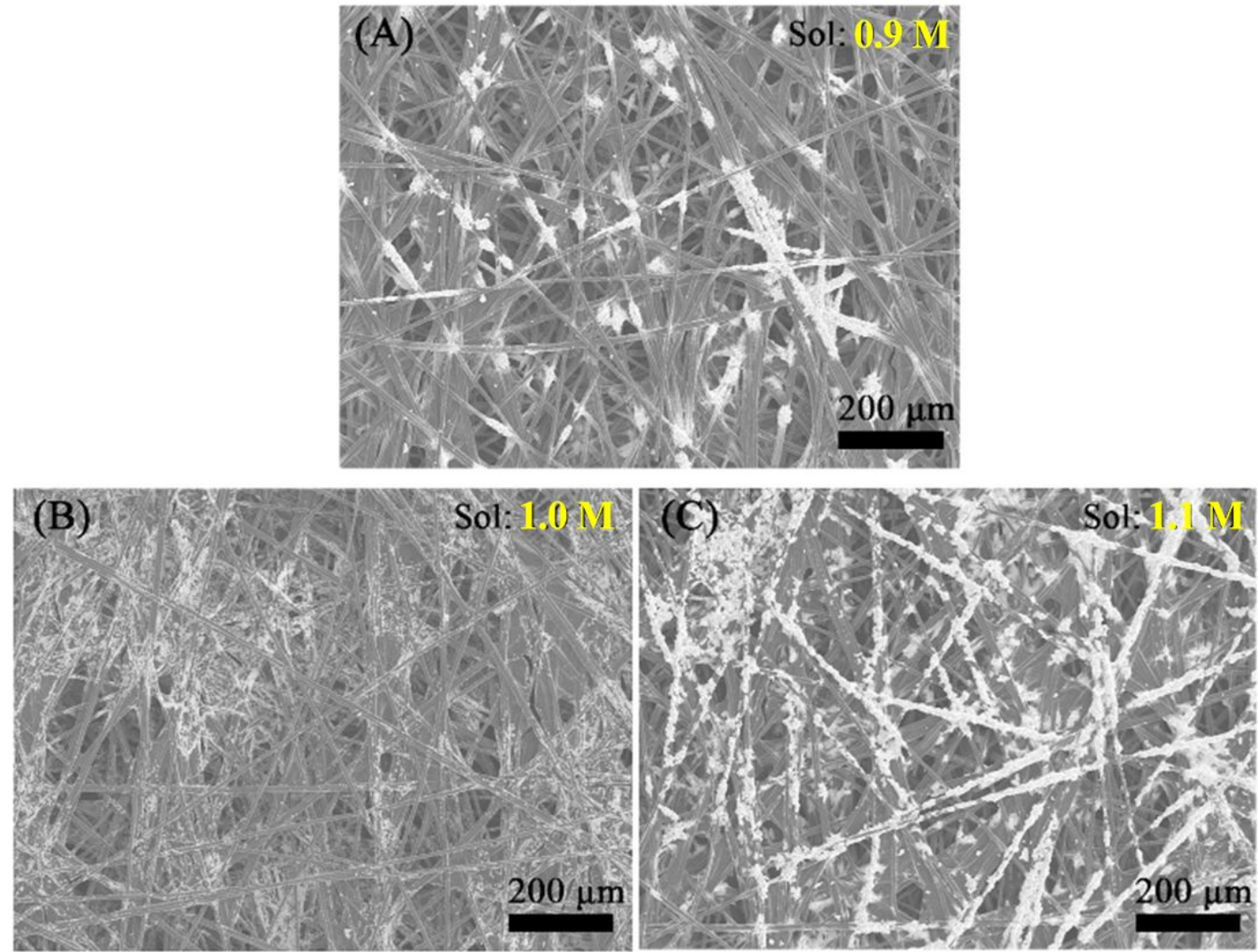

Figure S4. SEM images of $\mathrm{ZnO} / \mathrm{C}$-Sol samples prepared by soaking in different concentration of $\mathrm{Zn}\left(\mathrm{NO}_{3}\right)_{2}$ solution and calcination: (A) $0.9 \mathrm{M}$, (B) $1.0 \mathrm{M}$, (C) $1.1 \mathrm{M}$. 


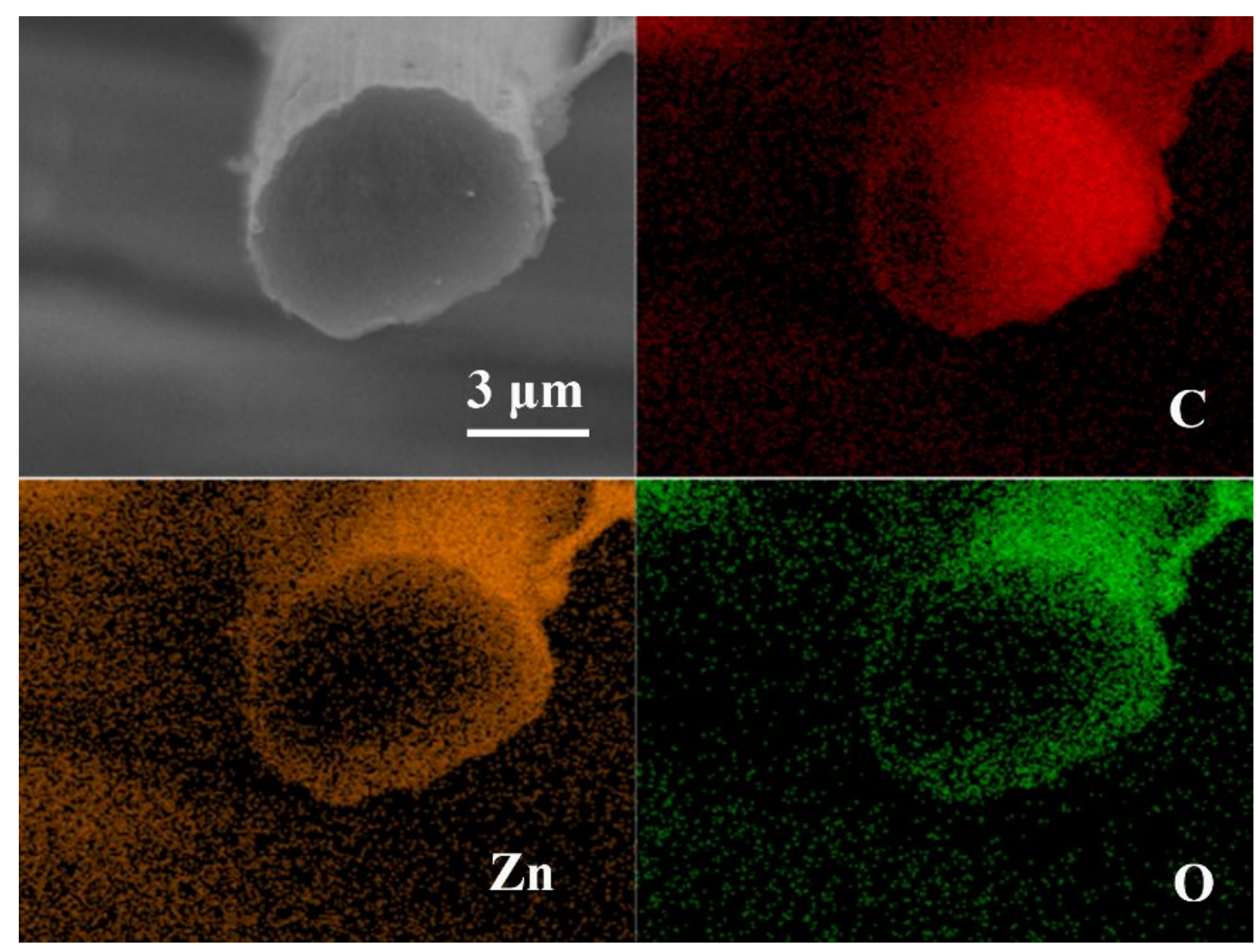

Figure S5. Cross-sectional elemental mappings for a single carbon fiber tube of $\mathrm{ZnO} / \mathrm{C}-\mathrm{ALD}$ electrode.

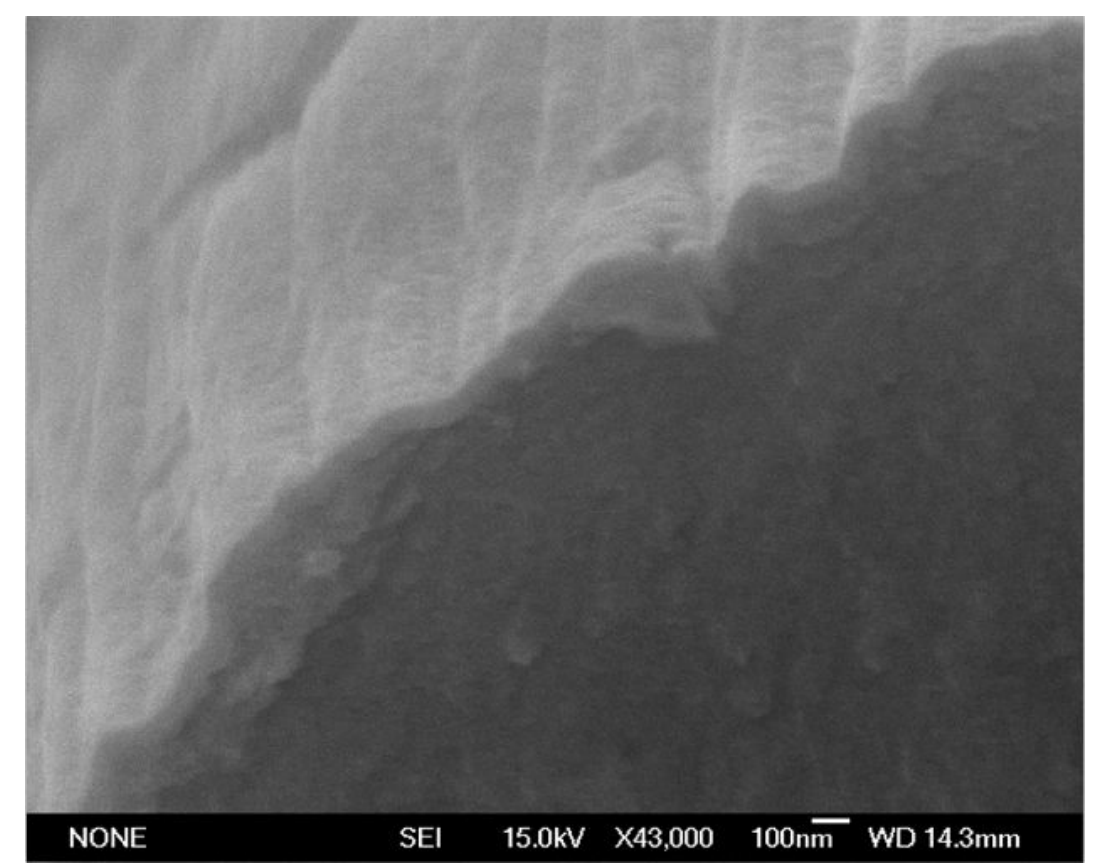

Figure S6. Enlarged SEM image of the $\mathrm{ZnO}$ coating layer for the $50 \mathrm{~nm}$ ALD-ZnO electrode. 


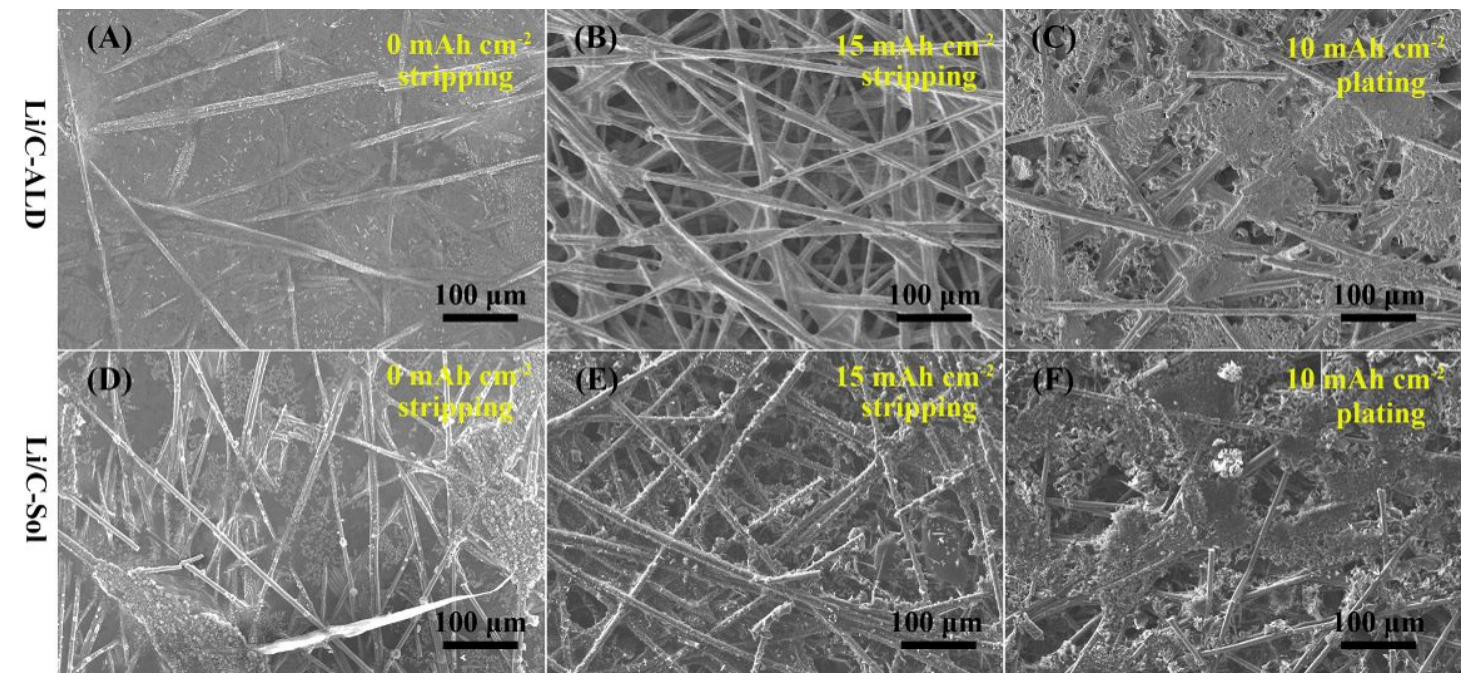

Figure S7. Top-view SEM images of Li/C-ALD (A-C) and Li/C-Sol (D-F) electrodes after stripping (A, D) $0 \mathrm{mAh} \mathrm{cm}^{-2}$, (B, E) $15 \mathrm{mAh} \mathrm{cm}^{-2}$, and plating (D, F) $10 \mathrm{mAh}$

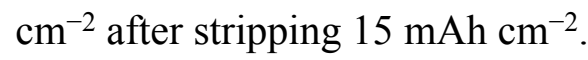



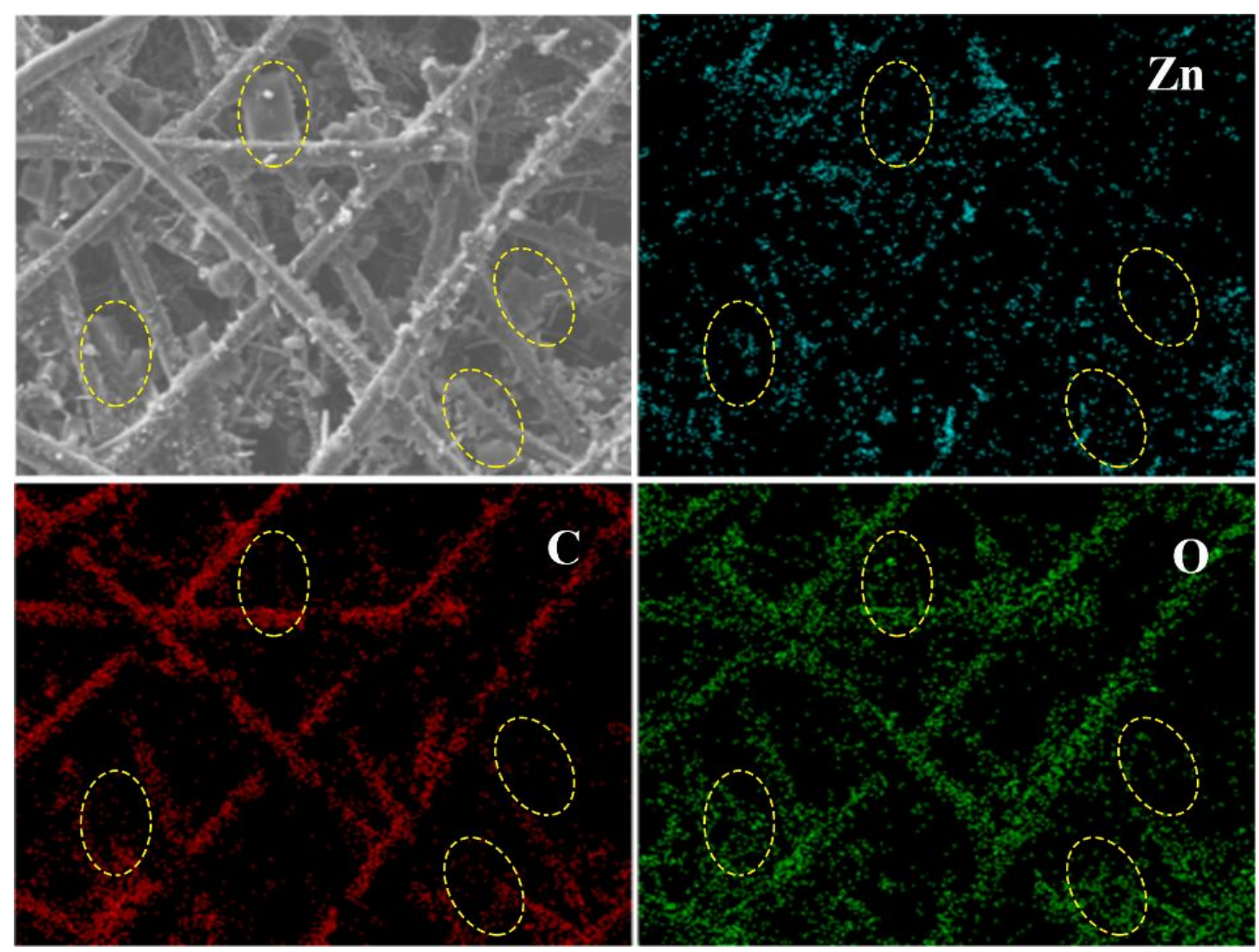

Figure S8. Elemental mappings for Li/C-Sol electrode after stripping $15 \mathrm{mAh} \mathrm{cm}^{-2}$. 

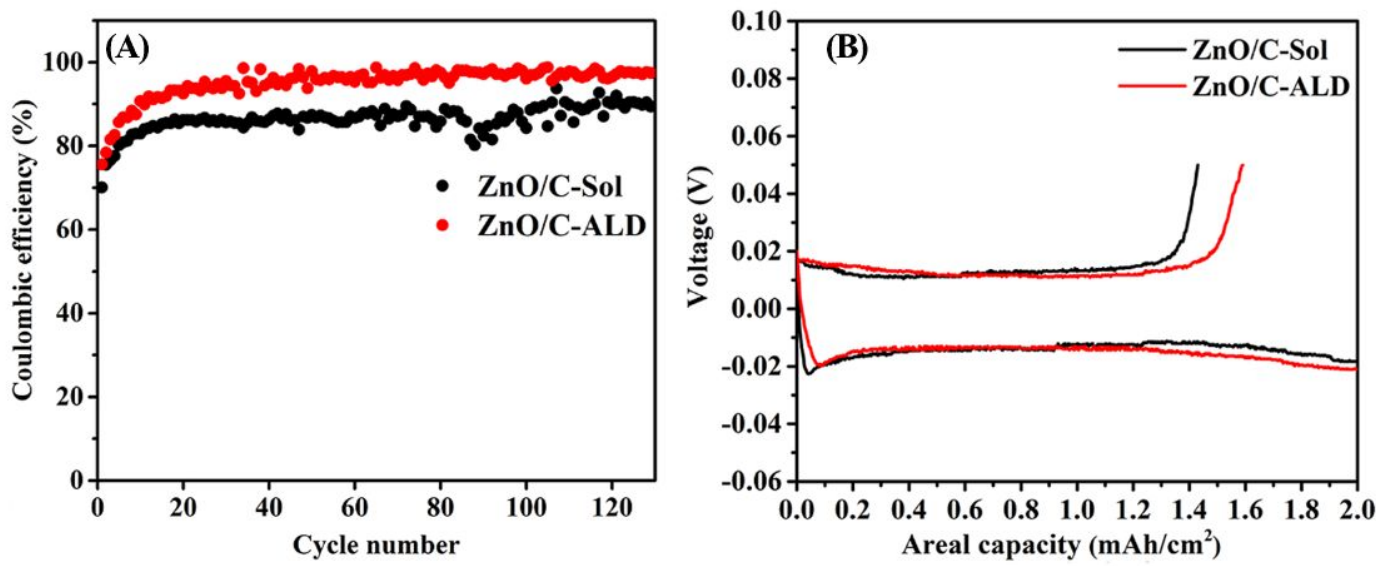

Figure S9. (A) Coulombic efficiency of $\mathrm{ZnO} / \mathrm{C}-\mathrm{Sol}$ and $\mathrm{ZnO} / \mathrm{C}-\mathrm{ALD}$ with Li metal as the reference/counter electrode with areal capacity of $5 \mathrm{mAh} \mathrm{cm}^{-2}$ at a current density of $1 \mathrm{~mA} \mathrm{~cm} \mathrm{~cm}^{-2}$. (B) Voltage profiles of the lithium deposition/dissolution process of $\mathrm{ZnO} / \mathrm{C}-\mathrm{Sol}$ and $\mathrm{ZnO} / \mathrm{C}-\mathrm{ALD}$ with $\mathrm{Li}$ metal as the reference/counter electrode at $1 \mathrm{~mA}$ $\mathrm{cm}^{-2}$ for $5 \mathrm{mAh} \mathrm{cm}^{-2}$. 

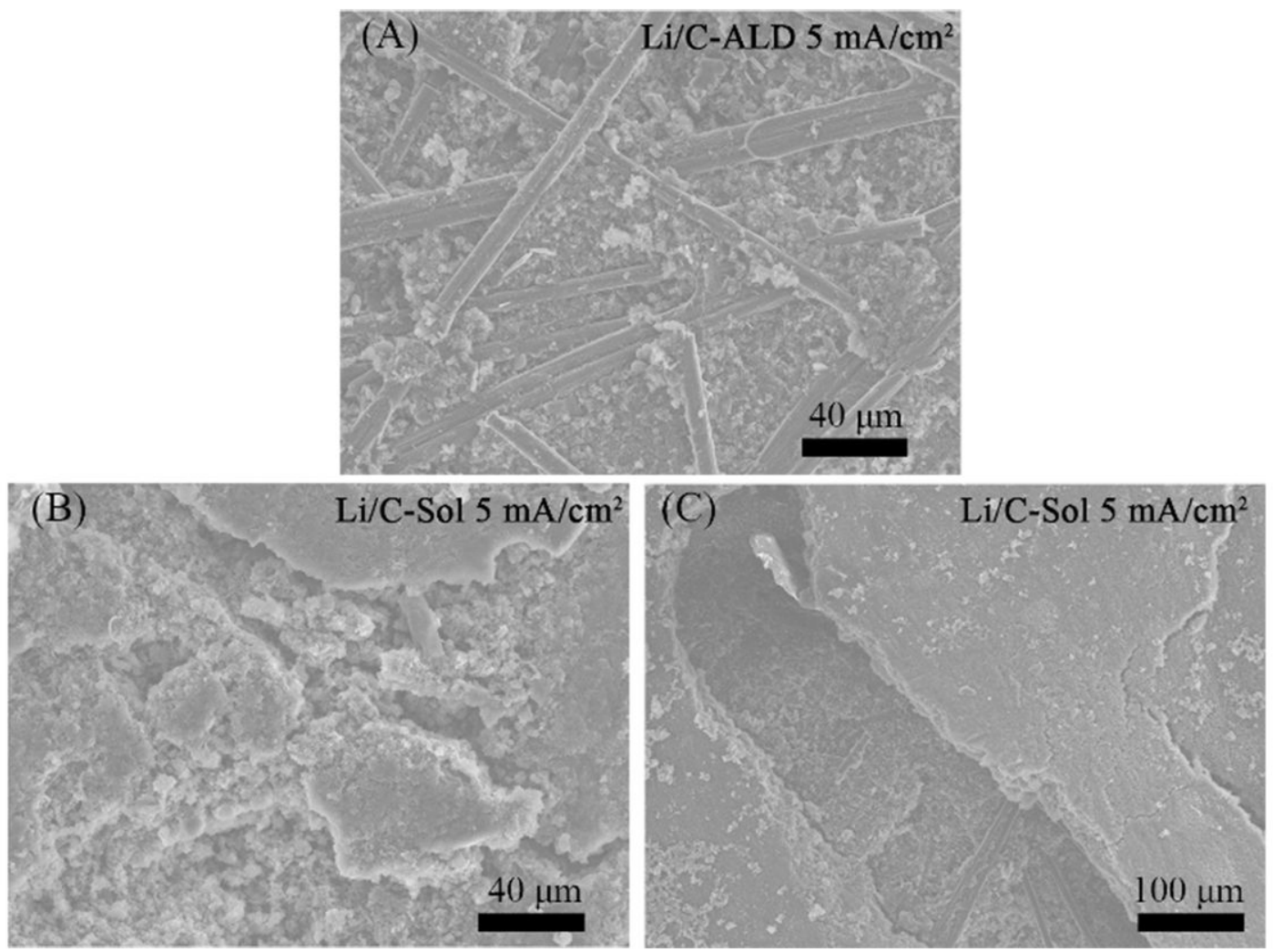

Figure S10. SEM images of (A) Li/C-ALD and (B, C) Li/C-Sol electrodes after 200 cycles at a current density of $5 \mathrm{~mA} \mathrm{~cm}^{-2}$.

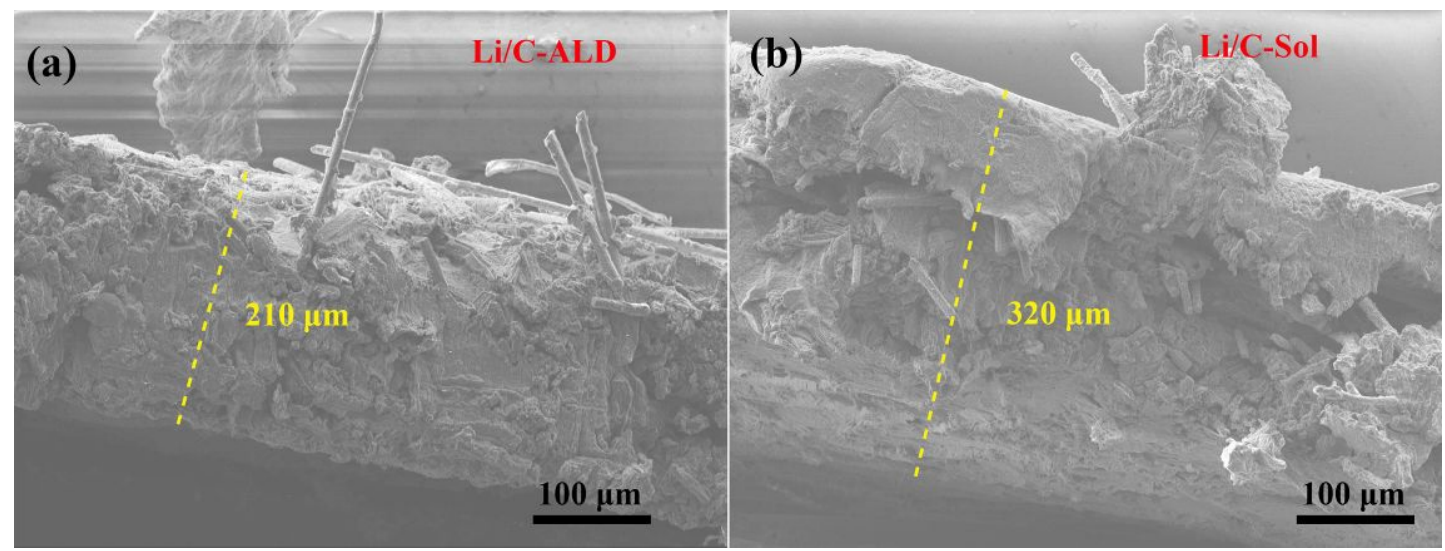

Figure S11. The cross-sectional SEM images of (A) Li/C-ALD and (B) Li/C-Sol electrodes after 200 cycles at a current density of $5 \mathrm{~mA} \mathrm{~cm}^{-2}$. 